\title{
Implante de tubo de silicone com e sem colágeno na regeneração de nervos em eqüinos
}

\author{
Implant of silicone tube with or without collagen in nerve regeneration of horses
}

\author{
Nádia Delistoianov ${ }^{I}$ Rodrigo Norberto Pereira' ${ }^{\mathrm{I}}$ Paula Alessandra Di Filippo ${ }^{\mathrm{I}}$ \\ Renata Gebara Sampaio DóriaI Antonio Carlos Alessi ${ }^{I I}$
}

RESUMO

A reconstituição cirúrgica de nervos em humanos, em cães e em diversos animais de laboratório é bastante utilizada e tem indicações clínicas e experimentais importantes. No entanto, em eqüinos há poucas informações sobre esta prática. Há relatos sobre a excessiva proliferação de tecido conjuntivo e a formação de neuromas à neurorrafia experimental, mesmo quando se utilizam tubos de silicone para condução do crescimento axonal. O presente estudo teve o objetivo de acrescentar informações sobre o processo de reparação de nervos periféricos em eqüinos por meio de implante de tubo de silicone preenchido ou não com colágeno. Para tanto, foram utilizados oito eqüinos, alocados em dois grupos: GI-13 semanas e GII-26 semanas de observação. Foi realizada secção dos nervos ulnares (NUs) e dos ramos cutâneos laterais dos 17o nervos torácicos (NTs), bilateralmente, seguindo tubulização, realizada em cada animal, alternando-se tubos de silicone vazios (TS), em um dos antímeros, ou preenchidos com solução de colágeno (TSC), no contralateral, deixando-se um espaço de $5 \mathrm{~mm}$ entre os cotos. Nenhuma alteração foi encontrada ao exame do aparelho locomotor e as primeiras reações positivas ao teste de sensibilidade cutânea nos NUs e NTs com TS e TSC foram observadas a partir da $9^{a}$ semana, em ambos os grupos. Ao final do período de observação, verificou-se, macroscopicamente, que os nervos encontravam-se envolvidos por tecido conjuntivo e o interior da câmara estava preenchido por tecido de coloração esbranquiçada, de forma cilíndrica, interligando os cotos proximal e distal. Microscopicamente, constatou-se a presença de axônios mielinizados interligando os cotos, as células de Schwann e o processo de remielinização do coto distal, principalmente no TSC. Em ambos os grupos, não houve formação de neuromas e o processo inflamatório limitou-se às áreas perineurais. Concluiu-se que o implante de tubo de silicone conduz à regeneração de NUs e NTs de eqüinos sem formação de neuromas e que a adição de colágeno promove aumento do número de fibras mielinizadas.
Palavras-chave: regeneração de nervos, implante, tubo de silicone, colágeno, eqüino.

\begin{abstract}
Surgical nerve repair in humans, dogs and laboratory animals is widely utilized for important clinical and experimental purposes. However, in horses there is scarce information. Neuroma and excessive conjunctive proliferation are reported. The aim of the present study was to add information about the repair process utilizing implant of silicone tubes with or without collagen in nerve regeneration of horses. Eight horses were allocated in two groups: GI-13 weeks and GII-26 weeks of observation. A complete section of the ulnar nerves (UNs) and of the lateral cutaneous branch of the $17^{\text {th }}$ thoracic nerves (TNs), bilaterally, was followed by repair with silicone tubes alternately filled with (STC) or without collagen (ST), with a $5 \mathrm{~mm}$ gap between stumps. Clinical evaluation was performed weekly, by cutaneous sensitivity testing of the region innervated by the respective operated nerves and physical examination of the thoracic limbs. No alterations were found in the locomotor apparatus. The first positive reactions to the cutaneous test occurred at the $9^{\text {th }}$ week post-surgery. At the end of the observation period it was verified, grossly, that the nerves were involved by conjunctive tissue and the lumen of the tube was filled by a whitish tissue, in a cylindrical shape. The ends nerves were interconnected. Microscopically, myelinated axons and Schwann cells were present in the gap between the stumps. In the GII the number of myelinated fibers was greater. The distal nerve showed remyelination process. There was no presence of neuroma and the inflammatory process was limited to the perineural areas. It was concluded that the implant of silicone tubes results in regeneration of UNs and TNs of horses without formation of neuromas and that de addition of collagen promotes an increase in the number of myelinated fibers.
\end{abstract}

Key words: nerve regeneration, implant, silicone tube, collagen, equine.

IPrograma de Pós-graduação em Cirurgia Veterinária, Faculdade de Ciências Agrárias e Veterinárias (FCAV), Universidade Estadual Paulista (UNESP), Jaboticabal, SP, Brasil.

IIDepartamento de Patologia Veterinária, FCAV/UNESP. Via de Acesso Prof. Paulo Donato Castellane, s/n, 14884-900, Jaboticabal,

SP, Brasil. E-mail: alessi@fcav.unesp.br. Autor para correspondência. 


\section{INTRODUÇÃO}

A reparação cirúrgica das injúrias dos nervos periféricos é um problema clínico comum e continua sendo um grande desafio para os cirurgiões (CHEN et al., 2006b; LI et al., 2006). A reconstrução pode ser realizada utilizando-se auto-enxertos. Entretanto, esta técnica apresenta desvantagens, tais como o tempo cirúrgico prolongado, a perda da função do nervo doado, a disponibilidade limitada de nervos e a combinação inadequada do diâmetro e da organização fascicular entre o nervo lesado e o enxerto. Sendo assim, pesquisas têm se concentrado no desenvolvimento de canais artificiais para a orientação nervosa (ITOH et al., 1999; CHEN et al., 2006a). Variados tipos de materiais, sintéticos ou biológicos, têm sido desenvolvidos para essa finalidade. Desses materiais, o tubo de silicone vem sendo usado clínica e experimentalmente por não causar modificação física no tecido, ser quimicamente inerte, não ser carcinogênico, não causar reação alérgica ou de corpos estranhos e ter capacidade de resistência a forças mecânicas (KAFEJIAN et al., 1997).

Os tubos de silicone proporcionam orientação aos axônios em processo de regeneração, prevenindo o seu escape para os tecidos circunjacentes, e impedindo a formação de neuromas. Além disso, eles isolam o microambiente, possibilitando o acúmulo de fatores tróficos e de crescimento, reduzem a invasão de tecido conjuntivo entre os cotos, direcionam a vascularização longitudinal aos vasos intraneurais e promovem uma orientação longitudinal do tecido cicatricial e da bainha epineural (FIELDS et al., 1989; DANIELSSON et al., 1996; LABRADOR et al., 1998; CHEN et al., 2006a). Os tubos de silicone permitem também que várias substâncias estimulantes, tais como o fator de crescimento nervoso - NGF (XU et al., 2003), o colágeno, a laminina, ou a fibronectina (LABRADOR et al., 1998; CHEN et al., 2000), as células de Schwann (PHILLIPS et al., 2005) e as células tronco de medula óssea (CHEN et al., 2006b) sejam introduzidas no lúmen dos tubos, entre os cotos nervosos, para acelerar o crescimento axonal.

O colágeno serve como substrato para a migração e a adesão de células de Schwann e para o crescimento regenerativo dos axônios e é amplamente utilizado em diversos modelos experimentais com resultados positivos (SATOU et al., 1986; DA-SILVA, 1993; LABRADOR et al., 1998; VERDU et al., 2002; MURAKAMI et al., 2003; PHILLIPS et al., 2005). Dessa forma, tendo em vista a dificuldade da reparação dos nervos digitais palmares em eqüinos (DELISTOIANOV et al., 2006), o presente estudo propôs-se a reestudar o processo de regeneração de nervos periféricos em eqüinos incluindo o uso de implante de tubo de silicone com ou sem colágeno. Para tanto, foram eleitos os nervos ulnares (NUs) e os ramos cutâneos laterais dos 17ํㅡㄹ nervos torácicos (NTs). A avaliação foi clínica, eletrofisiológica, macroscópica e histológica.

\section{MATERIAL E MÉTODOS}

Oito eqüinos adultos, de sete a nove anos de idade, clinicamente hígidos, com peso entre 300 e $450 \mathrm{~kg}$, avaliados por exame clínico e laboratorial foram alocados em dois grupos (GI e GII) com quatro animais em cada grupo, segundo o tempo de observação e coleta das biópsias. Esse tempo para o grupo GI foi de 13 semanas e para o GII foi de 26 semanas.

Após jejum de $12 \mathrm{~h}$, os animais foram sedados com cloridrato de xilazina $10 \%\left(0,5 \mathrm{mg} \mathrm{kg}^{-1}\right.$, IV). Decorridos 10 minutos, administrou-se éter gliceril guaiacol a 10\% (100 $\mathrm{mg} \mathrm{kg}^{-1}$, IV) em soro glicosado 5\%, sob pressão até o decúbito. A indução anestésica foi realizada com cetamina $10 \%\left(1 \mathrm{mg} \mathrm{kg}^{-1}\right.$, IV) e os animais foram posicionados em decúbito dorsal, intubados e mantidos sob anestesia geral inalatória com halotano sob ventilação espontânea em circuito semifechado.

Após o acesso ao nervo ulnar (NU) e ao nervo torácico (NT) de um dos lados do animal, foi iniciado o procedimento de fixação do tubo de silicone ${ }^{a}$ de diâmetro interno entre 1,5 e 2,5mm de acordo com o diâmetro do nervo, com auxílio de lupa de pala ${ }^{\mathrm{b}}$ de aumento de 2,5x. Inicialmente, foi passado um fio de náilon 6-0 agulhado pela parede do tubo de silicone a $5 \mathrm{~mm}$ de uma das extremidades, seguindo-se pelo lúmen até o meio externo. Em seguida, o mesmo fio foi passado pelo epineuro do nervo, retornando pelo interior do lúmen do tubo e foi exteriorizado por meio da parede a $2 \mathrm{~mm}$ lateralmente ao ponto inicial da sua entrada. Após realizar-se este procedimento nas duas extremidades do tubo de silicone, foi realizada a secção completa dos referidos nervos, entre os pontos passados pelo epineuro. Em seguida, os cotos foram tracionados pelos fios, sendo introduzidos no tubo de silicone. Ato contínuo, realizou-se a fixação dos fios de náilon por meio de nós cirúrgicos simples. Como o tubo tinha comprimento total de $2 \mathrm{~cm}$, obteve-se, ao final do procedimento, um espaço de $5 \mathrm{~mm}$ entre as extremidades dos cotos. Nos nervos contralaterais, foram realizados os mesmos procedimentos, acrescentando-se, no entanto, solução de colágeno ${ }^{\mathrm{c}}$, em concentração de $3,0 \mathrm{mg} \mathrm{mL}^{-1}$, injetada com seringa e agulha diretamente na luz do tubo de silicone, preenchendo-o totalmente, incluindo-se o espaço entre as extremidades dos cotos (grupo TSC). A seguir, realizou-se sutura de reaproximação do subcutâneo com fio de poliglactina 
1-0 e sutura de pele em pontos simples separados com fio sintético inabsorvível Supramid ${ }^{\circledR} 1$.

Durante o pós-operatório foi realizada bandagem no antebraço e antibioticoterapia sistêmica com penicilina benzatina (30.000UI kg $\left.{ }^{-1}, \mathrm{IM}\right)$ em três aplicações a cada 48 horas, e fenilbutazona $\left(4,4 \mathrm{mg} \mathrm{kg}^{-1}\right.$, IV) em quatro aplicações, a cada 24 horas. Os curativos foram realizados diariamente com iodopovidona até a remoção da bandagem e sutura de pele, com 7 e 10 dias, respectivamente.

Todos os animais foram submetidos semanalmente ao exame físico do aparelho locomotor (avaliação de claudicação e aspectos neurológicos gerais) e teste de sensibilidade cutânea utilizando uma pinça anatômica (SPEIRS, 1999). O teste de sensibilidade cutânea foi realizado pelo pinçamento de pele da região inervada pelos nervos ulnares (NUs) e pelos ramos cutâneos laterais dos $17^{\circ}$ nervos torácicos (NTs), que, segundo GODINHO \& GETTY (1986), compreende as regiões caudolateral e caudomedial do antebraço e a região do flanco, respectivamente. Contrações musculares após repetidos pinçamentos eram interpretados como reação positiva.

Os animais foram novamente submetidos à anestesia geral inalatória durante a $13^{\mathbf{a}}$ semana no GI e a $26^{\mathbf{a}}$ semana no GII, para avaliação da recuperação motora por eletroneuroestimulação e para a realização das biópsias. Os NUs e os NTs foram expostos, avaliados macroscopicamente e os tubos de silicone retirados após cuidadosa incisão longitudinal da sua parede, realizada com lâmina de bisturi. Estímulos elétricos ${ }^{\mathrm{d}}$, para avaliação da resposta motora, foram aplicados, por meio de agulhas finas, nos segmentos nervosos proximal e distal e no cabo de regeneração dos NUs e NTs. Utilizou-se onda bipolar regular com freqüência fixa de $10 \mathrm{~Hz}$. Contrações de feixes musculares seguidas ao estímulo elétrico no segmento distal foram interpretadas como resposta positiva.

Após a coleta dos segmentos, de aproximadamente $7 \mathrm{~cm}$, estes foram fixados em formalina a $10 \%$, tamponada com fosfatos, $\mathrm{pH} 7,4$, por um período de $18 \mathrm{~h}$. Fragmentos foram incluídos em parafina, seguindo-se de obtenção de cortes transversais e longitudinais de $5 \mu \mathrm{m}$ de espessura, que foram corados pelo método da Hematoxilina e Eosina ou Tricrômio de Masson.

\section{RESULTADOS}

No exame físico do aparelho locomotor, tanto na avaliação de claudicação quanto nos aspectos neurológicos gerais, nenhuma alteração foi registrada durante todo o período de observação, tanto nos eqüinos do GI quanto nos eqüinos do GII.

As primeiras reações positivas ao teste de sensibilidade cutânea nas regiões inervadas pelos NUs e NTs foram observadas a partir da $9^{a}$ semana após procedimento cirúrgico, representadas respectivamente pela retirada do membro do solo e pelos tremores cutâneos na região do flanco. Os animais dos GI e GII com TS e TSC, ao final do período experimental, apresentaram respostas positivas ao teste de pinçamento, conforme tabela 1 .

Durante a realização das biópsias, em ambos os grupos, observou-se, na região perineural, formação de tecido conjuntivo fibroso acompanhado de rica rede de vasos neoformados. O tecido conjuntivo fibroso foi incidido para que se pudesse ter acesso ao tubo de silicone. Em um NU do GI com TSC, contatou-se ausência do tubo de silicone devido à formação de uma fístula no pós-operatório e, em um NT do GII com TSC, constatou-se deiscência da sutura dos cotos com posicionamento lateral destes. Esses nervos não foram testados ou coletados.

Após a retirada do tubo de silicone, foi observada estrutura esbranquiçada cilíndrica, com a mesma coloração do nervo, interligando os cotos proximal e distal dos NUs (Figura 1) e NTs. Essa estrutura constituiu o cabo de regeneração.

O número de respostas positivas aos estímulos elétricos estão sumarizadas na tabela 2 . A resposta aos estímulos no segmento proximal do NU

Tabela 1 - Reações positivas ao teste de pinçamento de pele em eqüinos submetidos a reparação cirúrgica de nervos com tubos de silicone sem colágeno (TS) ou com colágeno (TSC). GI - período de observação de 13 semanas e GII - período de observação de 26 semanas.

\begin{tabular}{|c|c|c|c|c|c|c|c|c|}
\hline \multirow{2}{*}{ Semana/grupo } & \multicolumn{2}{|c|}{------9a*------ } & \multicolumn{2}{|c|}{------10 $0^{\mathrm{a}}$----- } & \multicolumn{2}{|c|}{------13a ------ } & \multicolumn{2}{|c|}{$------26^{\mathrm{a}}-----$} \\
\hline & NUs** & NTs & NUs & NTs & NUs & NTs & NUs & NTs \\
\hline GI - TS & $3 / 4$ & $4 / 4$ & $4 / 4$ & $4 / 4$ & $4 / 4$ & $4 / 4$ & ---- & ---- \\
\hline $\mathrm{GI}-\mathrm{TSC}$ & $3 / 4$ & $4 / 4$ & $4 / 4$ & $4 / 4$ & $4 / 4$ & $4 / 4$ & ---- & ---- \\
\hline GII - TS & $3 / 4$ & $4 / 4$ & $4 / 4$ & $4 / 4$ & $4 / 4$ & $4 / 4$ & $4 / 4$ & $4 / 4$ \\
\hline GII - TSC & $3 / 4$ & $4 / 4$ & $4 / 4$ & $4 / 4$ & $4 / 4$ & $4 / 4$ & $4 / 4$ & $4 / 4$ \\
\hline
\end{tabular}

* NUs - nervos ulnares; NTs - ramos cutâneos laterais dos 17ำ nervos torácicos. 


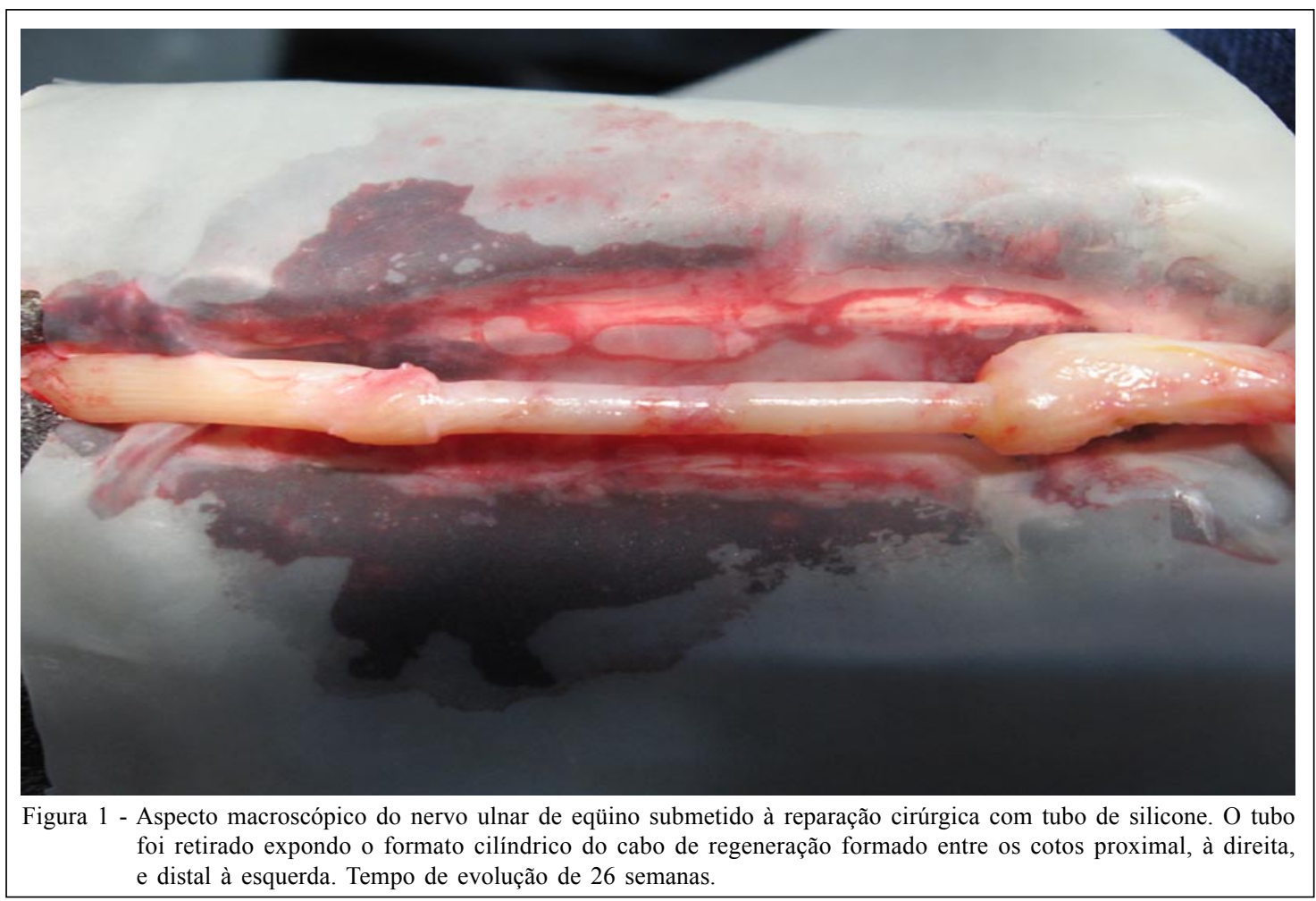

constitui essencialmente em contrações do músculo flexor ulnar do carpo e no NT constitui em contrações do músculo oblíquo externo do abdome.

Microscopicamente, os segmentos de nervos proximais dos NUs e dos NTs dos GI e GII com TS e TSC apresentaram, em cortes transversais e longitudinais, epineuro e perineuro característicos e axônios mielinizados, com morfologia muito próxima do normal. A mielina ficou muito bem evidenciada pelo Tricrômio de Masson. Nos segmentos distais, havia clara redução da mielina, presença de degeneração

Tabela 2 - Respostas positivas à eletroneuroestimulação (EN) e a presença de fibras nervosas (FN) no cabo de regeneração ao final do período experimental em eqüinos submetidos à reparação cirúrgica de nervos com tubos de silicone sem colágeno (TS) ou com colágeno (TSC). GI - período de observação de 13 semanas e GII período de observação de 26 semanas.

\begin{tabular}{lcccc}
\hline \multirow{2}{*}{ Grupo experimental / nervos } & \multicolumn{2}{c}{---NUs*--- } & \multicolumn{2}{c}{---NTs*--- } \\
& EN & FN & EN & FN \\
\hline GI - TS & $0 / 4$ & $4 / 4$ & $0 / 4$ & $3 / 4$ \\
GI - TSC & $1 / 3$ & $3 / 3$ & $0 / 4$ & $2 / 4$ \\
GII - TS & $3 / 4$ & $4 / 4$ & $3 / 4$ & $3 / 4$ \\
GII - TSC & $3 / 4$ & $4 / 4$ & $1 / 3$ & $3 / 3$ \\
\hline
\end{tabular}

* NUs - nervos ulnares; NTs - ramos cutâneos laterais dos 17응 nervos torácicos. walleriana, tumefação axonal e redução do diâmetro dos fascículos, células de Schwann dispostas em desarranjo e axônios pouco visíveis, mais finos. No entanto, os segmentos distais dos NUs e dos NTs dos GI e GII com TSC em cortes transversais e longitudinais apresentaram visivelmente uma maior quantidade de axônios mielinizados e em processo de remielinização quando comparados aos nervos com TS.

Os cabos de regeneração (Tabela 2) dos NUs e NTs com TS e TSC do GI apresentaram em cortes transversais pequenos fascículos delimitados por tecido conjuntivo em quantidade variável, com presença de fibras nervosas e células de Schwann. As fibras nervosas, quando visíveis, apresentaram-se mais finas comparadas ao segmento proximal do mesmo nervo. Nos cabos de regeneração do GII com TS e TSC em cortes longitudinais, havia notável proliferação de fibras nervosas, em fascículos, e de células de Schwann do segmento proximal ao distal com orientação paralela. Os cabos de regeneração com TSC apresentaram uma quantidade de fibras mielinizadas cerca de $30 \%$ superior quando comparadas aos cabos com TS (Figuras 2 e 3). Nos cortes longitudinais, uma contagem de fibras mielinizadas indicava essa diferença.

Os segmentos proximais, distais e cabos de regeneração dos NUs e NTs com TS e TSC em cortes longitudinais apresentaram infiltrado inflamatório difuso 


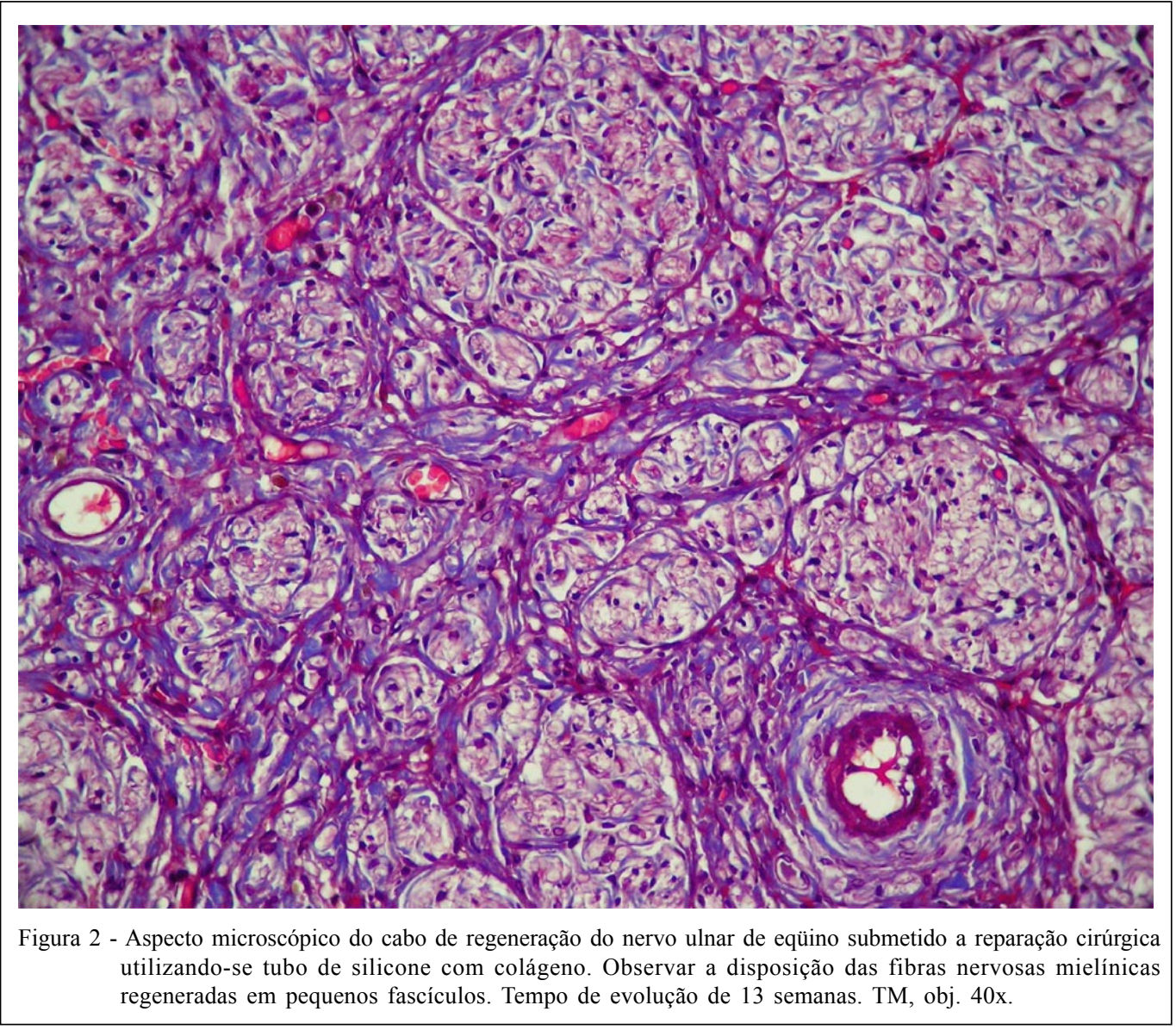

de células mononucleares e eosinófilos nos dois grupos, de moderado a acentuado, no local de contato do feixe nervoso com o tubo de silicone. Não foi observado infiltrado inflamatório nos segmentos proximais e distais fora das áreas próximas ao tubo.

\section{DISCUSSÃO}

O processo de reparação de nervos em eqüinos sofre interferências diversas, tais como a índole do animal, a dificuldade de imobilização e a proliferação excessiva de tecido conjuntivo, que dificultam o processo (DELISTOIANOV et al., 2006). No entanto, no presente trabalho, pôde-se verificar que a reparação cirúrgica de nervos, em um procedimento experimental, mostrou-se viável. $\mathrm{O}$ cuidado em não traumatizar os nervos, adotando-se a secção do nervo após a passagem do fio pelo epineuro e facilitando sua tração ao interior do tubo, deve ter contribuído positivamente. A avaliação clínica, a eletroneuroestimulação direta e as avaliações macro e microscópicas evidenciaram que a regeneração morfológica e funcional é possível também nos cavalos. A utilização dos recursos freqüentemente utilizados em outras espécies e também no homem, tais como tubo de silicone e solução de colágeno (SATOU et al., 1986; DASILVA, 1993; LABRADOR et al., 1998; VERDU et al., 2002; MURAKAMI et al., 2003; PHILLIPS et al., 2005) permitiram o processo de regeneração. A imobilização, difícil para a espécie eqüina e apontada pelo trabalho de DELISTOIANOV et al. (2006) como uma das causas de insucesso, foi minimizada neste trabalho pela escolha dos nervos de regiões de menor movimentação, ou seja, o NU e o NT. O período requerido para regeneração é superior ao de outras espécies, conforme relatam LE BEAU et al. (1988), CONTESINI et al. (1992), no entanto, com 13 semanas, já se encontrou cabos de regeneração muito bem formados.

A utilização de colágeno favoreceu o processo de formação de fibras, notando-se, ao exame microscópico, cerca de $30 \%$ a mais de axônios mielinizados nos cabos e nos segmentos distais (Figura 3). Essa determinação será objeto de estudo complementar com reavaliação morfométrica, com utilização de inclusão em resina. A avaliação clínica também foi importante na confirmação da recuperação funcional. $\mathrm{Na} 9^{\underline{a}}$ semana foram observadas respostas a 

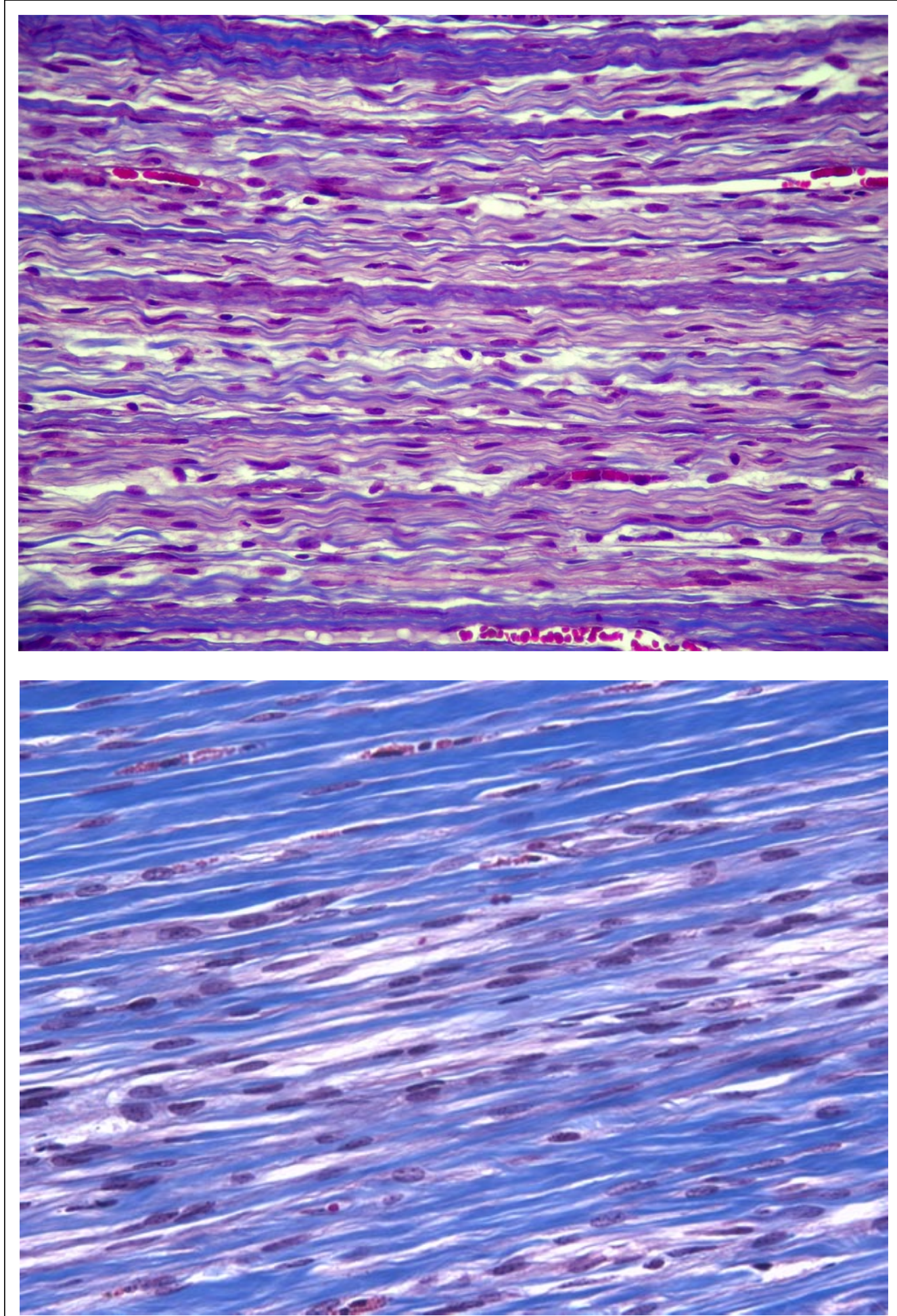

Figura 3 - Aspecto microscópico do cabo de regeneração do nervo ulnar de eqüino submetido à reparação cirúrgica utilizando-se tubo de silicone com (A) e sem (B) colágeno. Observar a disposição das fibras nervosas mielínicas em orientação longitudinal paralela, em maior número em A. Tempo de evolução de 26 semanas. TM, obj. 40x. 
estímulos de pinçamento de pele. Esse tempo está de acordo com o que ocorre com cães STOPIGLIA (1992). No entanto, a eletroneuroestimulação mostrou resultados de difícil interpretação. Na literatura não se encontram trabalhos sobre esse procedimento em eqüinos, mas sim para outras espécies, com mensuração do potencial evocado e da velocidade de condução do nervo (LABRADOR et al., 1998; MURAKAMI et al., 2003; IKEGUCHI et al., 2006). Portanto, a utilização de metodologia adaptada pode não ter sido a mais indicada. Este é um assunto que merece mais estudos.

A observação macro e microscópica mostrou que o tubo de silicone proporcionou uma orientação aos axônios em regeneração e impediu a invasão de tecido conjuntivo entre os cotos e a formação de neuroma (DELISTOIANOV et al., 2006), corroborando os resultados de FIELDS et al. (1989), LABRADOR et al. (1998) e DAHLIN et al. (2001) em outras espécies. O cabo de regeneração apresentou características macroscópicas semelhantes às encontradas por STOPIGLIA (1992) em cães, CHEN et al. (2000); IKEGUCHI et al. (2006) em ratos.

A utilização de um intervalo de $0,5 \mathrm{~cm}$ entre os cotos, também utilizado por DAHLIN et al. (2001) e CHEN et al. (2006b), no momento da neuropexia ao tubo de silicone, mesmo correndo o risco de degeneração do coto distal, foi acertada. Em outras espécies, estudos têm utilizado várias distâncias. No rato, espécie em que a regeneração é muito rápida, ou seja, quatro semanas, utiliza-se $1 \mathrm{~cm}$ ou até mais (CHEN et al., 2000; IKEGUCHI et al., 2006). Nesse caso, não há tempo para haver degeneração do coto distal. No eqüino, uma distância muito reduzida (DELISTOIANOV et al., 2006) não melhora o processo. A presença de infiltrado inflamatório junto aos cotos e ao cabo de regeneração foi discreta e não comprometeu o processo.

\section{CONCLUSÕES}

Mediante a análise dos resultados obtidos neste estudo, foi possível concluir que a reparação com tubos de silicone nos NUs e nos NTs possibilita a regeneração nervosa periférica em eqüinos, sem formação de neuromas e com reduzida proliferação conjuntiva. $\mathrm{O}$ uso de colágeno favorece o processo de regeneração axonal. Os NUs e os NTs de eqüinos mostram-se viáveis como modelo experimental para o estudo da regeneração nervosa periférica.

\section{AGRADECIMENTOS}

À Fundação de Amparo à Pesquisa do Estado de São Paulo (Fapesp), (auxílio - proc. 04/06004-9); ao Conselho Nacional de Desenvolvimento Científico e Tecnológico (CNPq), pela concessão de bolsa de doutorado à Nádia Delistoianov. Às Sras. Francisca de A. Ardison e Maria I. Y. Campos, pela confecção das lâminas histológicas.

\section{FONTES DE AQUISIÇÃO}

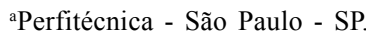

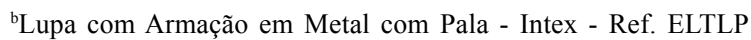
$28 \times 32$.

${ }^{c}$ Vitrogen - Collagen in Solution - Nutacon Ltda. - Nederland/ European.

${ }^{\mathrm{d}}$ Eletroestimulador - modelo AP585 - Biotherapy - São Carlos/ SP.

\section{COMITÊ DE ÉTICA E BIOSSEGURANÇA}

Trabalho aprovado pela Comissão de Ética e Bem Estar Animal da FCAV/UNESP - Número do protocolo: 01880005

\section{REFERÊNCIAS}

CHEN, Y.S. et al. Peripheral nerve regeneration using silicone rubber chambers filled with collagen, laminin and fibronectin. Biomaterials, v.21, n.5, p.1541-1547, 2000.

CHEN, M.H. et. al. An in vivo study of tricalcium phosphate and glutaraldehyde crosslinking gelatin conduits in peripheral nerve repair. Journal of Biomedical Materials Research. Part B, Applied Biomaterials, v.77, n.1, p.89-97, 2006 a.

CHEN, X. et. al. Study of in vivo differentiation of rat bone marrow stromal cells into Schwann cell-like cells. Microsurgery, v.26, n.2, p.111-115, 2006b.

CONTESINI, E.A. et al. Avaliação clínico-morfológica da regeneração nervosa periférica mediante alinhamento por tubo de silicone em caninos. Ciência Rural, v.22, n.1, p.65-71, 1992 .

DAHLIN, L.B. et. al. Tissue response to silicone tubes used to repair human median and ulnar nerves. Scandinavians Journal Reconstructive Surgery, v.35, n.1, p.29-34, 2001.

DANIELSSON, P. et al. Tubulization increases axonal outgrowth of rat sciatic nerve after injury. Experimental Neurology, v.139, n.2, p.238-243, 1996.

DA-SILVA, C.F. Tubos sintéticos para a regeneração de nervos. Ciência Hoje, v.16, n.94, p.85-86, 1993.

DELISTOIANOV, N. et. al. Comparação entre duas técnicas de neurorrafia do digital palmar em eqüinos. Arquivo Brasileiro de Medicina Veterinária e Zootecnia, v.58, n.1, p.44-51, 2006 .

FIELDS, R.D. et al. Nerve regeneration through artificial tubular implants. Progress in Neurobiology, v.33, n.2, p.87-134, 1989. 
GODINHO, H.P.; GETTY, R. Sistema nervoso periférico. In: GETTY, R. Anatomia dos animais domésticos. Rio de Janeiro:Guanabara Koogan, 1986. Cap.24, p.608-642.

IKEGUCHI, R. et al. Basic fibroblast growth factor promotes nerve regeneration in $\mathrm{C}$-ion-implanted silicon chamber. Brain Research, v.1090, n.1, p.51-57, 2006.

ITOH, S. et al. Synthetic collagen fibers coated with a synthetic peptide containing the YIGS sequence of laminin to promote peripheral nerve regeneration in vivo. Journal of Materials Science: Materials in Medicine, v.10, p.129-134, 1999.

KAFEJIAN, A.P. et al. Estudo comparativo das reações teciduais a implantação de silicone e politetrafluoroetileno no dorso de ratos. Acta Cirúrgica Brasileira, v.12, n.3, p.131-135, 1997.

LABRADOR, R.O. et al. Influence of collagen and laminin gels concentration on nerve regeneration after resection and tube repair. Experimental Neurology, v.149, n.1, p.243-252, 1998.

LE BEAU, J.M. et al. Extracellular fluid conditioned during peripheral nerve regeneration stimulates Schwann cell adhesion, migration and proliferation. Brain Research, v.459, n.1, p.93-104, 1988 .

LI, Q. et. al. Nerve conduit filled with GDNF gene-modified Schwann cells enhances regeneration of the peripheral nerve. Microsurgery, v.26, n.2, p.116-121, 2006.
MURAKAMI, T. et al. Transplanted neuronal progenitor cells in a peripheral nerve gap promote nerve repair. Brain Research, v.974, n.1-2, p.17-24, 2003.

PHILLIPS, J.B. et al. Neural tissue engineering: a selforganizing collagen guidance conduit. Tissue Engineer, v.11, n.9-10, p.1611-1617, 2005.

SATOU, T. et al. A morphological study on the effects of collagen gel matriz on regeneration of severed rat sciatic nerve in silicone tubes. Acta Pathology Japonica, v.36, n.2, p.199208, 1986.

SPEIRS, V.C. Exame clínico de eqüinos. Porto Alegre: Artmed, 1999. 366p.

STOPIGLIA, A.J. Estudo experimental comparativo da regeneração nervosa com o emprego de auto-enxerto a fresco e de tubo de silicone na reparação cirúrgica de falhas do nervo ulnar de cão (Canis familiaris). 1992. 116f. Tese (Livre Docência em Cirurgia Veterinária) - Faculdade de Medicina Veterinária e Zootecnia, Universidade de São Paulo

VERDU, E. et al. Alignment of collagen and laminin-containing gels improve nerve regeneration within silicone tubes. Restoration Neurology Neuroscience, v.20, n.5, p.169179, 2002.

$\mathrm{XU}, \mathrm{X}$. et al. Peripheral nerve regeneration with sustained release of poly (phosphoester) microencapsulated nerve growth factor within nerve guide conduits. Biomaterials, v. 24, n.13, p. $2405-2412,2003$. 